\title{
KIEN, CRAWFORD, BATEMAN Y DURDEN: LOS NOMBRES DE LA VIOLENCIA \\ José Mariano Leyva*
}

\section{Violencia interior, brutalidad aceptada y rudeza literaria}

\section{El día de hoy, hasta las venganzas} moderadamente violentas son un asco. La defensa del honor es un reloj de bolsillo que ya no funciona. Si un puñetazo se asesta certero, a cambio obtendremos el denigrante sello de salvajes, además de ricas dosis de vergüenza. Sin embargo, el día de hoy aún existen muchos motivos que ameritarían un buen puñetazo en la cara. El repudio a la violencia no está tan ligado a los orgullosos pilares de la civilización. Más bien comparte sitio con la apatía, con un individualismo que busca la protección antes que cualquier ataque. Pero la violencia interior está ahí por más apatía que generemos.

La mejor arma de la brutalidad real es hacer creer que no existe. Un país es bombardeado: ahí no hay rudeza, es una cruzada contra el terrorismo. A un país en la miseria se le venden armas para alimentar guerras intestinas: ahí no existe inmoralidad, es el espíritu de libre mercado contra un dictador. Violencia que ataca violencia tiene justificación en la conciencia. Pero no toda la violencia es consentida. La agresividad que alarma al chato mundo moderno suele ser la menos nociva: la que no existe, la imaginaria, la que comulga con el arte.

\footnotetext{
* Investigador de la Dirección de Estudios Históricos, INAH.
} 
Paradójicamente, la brutalidad real no existe, se disfraza, mientras que la rudeza irreal es peligrosísima.

Los niños ahorcados del artista plástico Maurizio Cattelan, que tanta conmoción causaron hace unos años, no significan que Cattelan quiera asesinar infantes o que nos exhorte a hacerlo. Lo sorprendente en la crítica que prestó atención a Cattelan fue que pocos hablaron de lo vacío de la propuesta (elaborada más bien para alarmar), o de la estética (imaginada al vapor). El mundo criticó la visión violenta y eso sólo dejaba ver la ausencia de visión artística del mundo. Cuando un artista utiliza sólo elementos escandalosos para llamarlos arte y el mundo pone el grito en el cielo, nos damos cuenta de una cosa: que el arte no tiene nada que ver. Con Bret Easton Ellis sucedió algo que podría sonar parecido: demasiados cayeron en la provocación. Ellis puso una piedra y muchos cayeron. Eso sólo demuestra la ausencia de perspectiva literaria.

La violencia aún pertenece a la esfera del tabú; por lo mismo, es necesario aclarar las ideas más básicas al respecto. Una mala interpretación puede despertar al cuáquero que todos llevamos dentro y hacer suponer que este texto es una apología de la violencia. En un mundo de términos relativos, envilecidos por ideologías de cartón, es necesario señalar lo elemental. Existen dos tipos de violencia: la real y la ficticia. Una y otra jamás serán lo mismo. Sus funciones pueden ser diametralmente opuestas.

¿Por qué Bret Easton Ellis escupe tanta violencia? Pueden existir varias respuestas. Tal vez sea una reacción natural a un mundo en el que un niño de 16 años ya ha visto 18,000 asesinatos por televisión. ${ }^{1}$ $\mathrm{O}$ bien, que el autor se sepa bien sus triquiñuelas comerciales e incluya en su texto los ingredientes necesarios para lograr una buena venta de libros.

${ }^{1}$ Cifra que nos entrega Douglas Coupland, basado en la revista Connoisseur de septiembre de 1989, en Generación X, 2000, Barcelona, Ediciones B. 
Me imagino una escena entre los escritores analizados que, de creerles a críticos conservadores, se acercaría a la verdad. Todos quieren ser un éxito de ventas. Todos manejan a la perfección las engañifas mercadotécnicas. Pero como buenos capos literarios, deben repartir las tajadas del pastel. El capo Bret Easton Ellis se queda con las sierras eléctricas y las mutilaciones. El gángster Chuck Palahniuk obtiene los golpes, el vandalismo y los terroristas. Frédéric Beigbeder, de la Vendetta Française, logra la tajada correspondiente a la brutalidad psicológica. Todos tienen sus dosis de rudeza, todos serán un éxito.

Me cuesta trabajo creer que esta imagen sea acertada. No dudo que los autores hayan obtenido su ración diaria de agresividad, pero generalmente aquellas personas que resultan ser tan influenciables por la violencia, se dedican a matar transeúntes al azar o al menos, a molestar a su mascota con el palo de la escoba. No desperdiciarían su tiempo escribiendo una novela. De la misma manera, el salvajismo como gancho mercadotécnico resulta efectivo sólo hasta cierto punto. Se trata de una promoción devaluada por la excesiva oferta. El mundo contemporáneo, que con tanto énfasis rechaza la brutalidad, la ofrece con singular alegría.

La violencia regalada en los libros no resulta tan atractiva como para satisfacer los instintos más básicos. ¿Qué excitación nos puede producir leer a Coupland y saber que el número de muertos que causa medio kilogramo de plutonio reducido a polvo e inhalado es de $42 \mathrm{mil}$ millones? Más aún, que la cantidad de plutonio existente en los Estados Unidos en kilos es de 172 mil y que si multiplicamos ambas cifras el total es de 16,000 billones de muertos. ${ }^{2} \mathrm{Si}$ de verdad queremos cortejar con la violencia, resulta más atractivo ver los noticieros, el canal Reality $T V$ con sus trepidantes persecuciones de policías reales contra maleantes reales. Los desplantes violentos de éstos y los golpes proporcionados con todo el peso de la ley de aquéllos. Cualquier brutalidad real en directo termina por desplazar a la ficticia. Leer literatura para satisfacer el morbo no funciona. Hay que embarcarse en la fastidiosa

\footnotetext{
${ }^{2}$ En este caso, el autor lo toma de Science Digest, julio de 1984.
} 
tarea de imaginar el cuadro. Además, como todo el mundo sabe, la realidad siempre supera a la ficción.

Otra respuesta al muestrario de violencia en estos autores se obtiene de Frédéric Beigbeder. En su libro Windows on the World, un ejercicio en el que se busca copiar la realidad a través de la ficción, hay un reclamo. La historia narrada es la del 11 de septiembre en las torres gemelas de Nueva York. El autor francés opina sobre un atentado que sucede en un país que no es el suyo, pero que produce las ilusiones que el resto del mundo desea. El país con el tipo de cultura al que el grueso de los gobiernos de Occidente aspira llegar. Un país que, por encontrarse a la vanguardia, contiene las contradicciones más definidas de ese futuro, de ese ideal. El atentado del 11 de septiembre en Estados Unidos pronto se volvió dilema universal, de la misma manera que se encuentra expandida la influencia estadounidense en el resto del globo. Como analiza Michel Houellebecq en Las partículas elementales, no existe ningún ejemplo de alguna moda venida de los Estados Unidos que no haya triunfado en Europa occidental algunos años más tarde. Houellebecq expone el inicio del proceso en los años setenta. Estados Unidos comienza a exportar con insistencia desde ideologías hasta siliconas para los pechos. Treinta años después, los demás países tenemos mucho que ver con esa sociedad, con sus contradicciones, sus supuestas corduras y sus discreciones impuestas, aunque existan muchos que no acepten de forma pasiva ese estilo de vida. Se entiende entonces que a Beigbeder le preocupe el atentado como si hubiera ocurrido en su propio país. Una misma cultura sembrada en distintos países, logra escritores disconformes y parecidos que atraen a lectores de diferentes latitudes. ${ }^{3}$

${ }^{3} \mathrm{Al}$ respecto, Ryu Murakami elabora un espeluznante relato: Sopa de miso, 2005, Seix Barral. Ahí, la violencia prodigada por un asesino serial sirve para analizar el choque cultural entre Estados Unidos y Japón. La adopción de los íconos norteamericanos sumerge a la cultura nipona en enigmas cargados de frivolidad, inocencia, ignorancia y contradicciones. El estilo literario de Murakami lo acerca a cualquier episodio violento del grupo de autores occidentales analizados. Una mirada a esos íconos la ofrece Palahniuk en Error humano, serie de crónicas que sintetizan buena parte de esa cultura: el sexo convertido en una actividad grupal 
En Windows on the World, cada capítulo corresponde a los minutos que transcurrieron desde las 8:30 hasta las 10:29 de aquella mañana. Un lapso que abarca desde los instantes anteriores al impacto del primer avión, hasta el derrumbe de ambas torres. A los minutos nones les corresponde la historia de un esposo divorciado que lleva a sus hijos a desayunar, ese aciago día, al restaurante que se encuentra en la cima de uno de los edificios: el Windows on the World. Ahí, la cultura norteamericana aparece remachada con los aguijones de crítica, para ser curada después con cortesías. En los minutos pares, el autor realiza un ejercicio ejecutado con anterioridad: hablar de sí mismo. Aparece esa constante necesidad por contarnos procesos personales como un exhibicionista de las ideas y vivencias en carne propia. El autor inicia su recorrido en el restaurante Le Ciel de Paris, en la Torre Montparnasse y lo termina en su visita al Ground Zero en Nueva York. Lo que ahí se refleja (como el autor dice) es la escéptica cultura francesa y (como el autor no dice) el mundo moderno desde la óptica de un autor contemporáneo.

El tema ya es lo bastante violento como para obligarnos a dudar. ¿Escribe Beigbeder porque los atentados lo impactaron también a él? Podemos creerlo si atendemos declaraciones como la siguiente: "Con la caída del muro se terminó el sistema socialista. Con la caída de las torres, se cayó el sistema capitalista." Pero podemos ser escépticos: ¿escribe Beigbeder para aprovechar el tema y lograr un éxito de ventas más? ¿Es un autor oportunista o un autor retratista? A mi parecer, el asunto se resuelve en el minuto 10:01.

Beigbeder habla de la cobertura mediática que tuvo el atentado. ¿Cuántas veces vimos caer las torres? Demasiadas. La repetición ha terminado por eliminar la violencia. La costumbre sustituye la emoción. El terror mostrado se parece más al pavor de celofán que pro-

y mecánica; el apetito por la destrucción de cosechadoras cuyos choferes mezclan patriotismo e ignorancia; el terror a lo desconocido, atomizado en dos personas que son agredidas por ir vestidos de botargas; el mantenimiento de la hipocresía en submarinos militares llenos de sodomitas que la opinión pública prefiere no ver. 
duce cualquier película de catástrofes norteamericanas. Aquellas que dejaron de filmar cuando la ficción se volvió el oráculo que anticipaba el futuro real. Lo que no se vio, o nos otorgaron en dosis minúsculas, fue la verdadera violencia. Dice Beigbeder:

No se ven los pedazos de gente que caían, las fuentes de sangre, el acero, la carne y el plástico soldados entre sí. Ustedes no olieron los cables eléctricos quemados, ese olor a cortocircuito multiplicado por 100,000 voltios. No oyeron los gritos animales, como de cerdos degollados, de terneras despedazadas vivas, excepto que no eran terneras sino cerebros humanos, capaces de suplicar. ${ }^{4}$

No sólo no las vimos, ni siquiera las intuimos. De pronto el World Trade Center eran dos compactos cuerpos de cemento y metal que caían una y otra vez. Nada de dilemas humanos.

Las reglas para algunos son bastante claras: es permisible mostrar la violencia sólo en algunos casos. La violencia en el mundo interconectado muta de valor. Aquella que se enseña, que es terrible, es de la que se puede sacar algún tipo de provecho, generalmente político. Sangre y vísceras en Panamá, una pantalla monocromática en verde para los bombardeos a Irak. No había razón para pigmentar al WTC con ese color, pero la salvaje realidad fue sustraída de su afectación violenta.

De pronto hay más violencia en los ficticios niños ahorcados de Cattelan que en uno de los peores atentados de la historia. Tal vez esto suceda porque dos edificios emblemáticos cayendo son suficiente para desatar una guerra, mientras que los restos humanos increparían al torpe gobierno que permitió la catástrofe. "Un edificio se derrumba y vemos infinitas veces el derrumbamiento. Pero no se les ocurra mostrar lo que había dentro: nosotros", dice el personaje de Windows on the World.

\footnotetext{
${ }^{4}$ Frédéric Beigbeder, Windows on the World, 2004, Barcelona, Anagrama, p. 269.
} 
Pues bien, Ellis, Palahniuk, Coupland y el mismo Beigbeder tienen una obsesión por mostrar lo que hay dentro. Sus historias muestran más las moles de cemento colapsando que los cuerpos carbonizados. A las buenas conciencias suele molestarles. Ellas son capaces de asistir a mítines contra la violencia de los artistas y los escritores, mientras dejan a sus hijos enchufados a la televisión, viendo un asesinato tras otro. Pero esto último no es problemático mientras los dispensadores de violencia victimen a extraterrestres color verde, cubanos color rojo o fumadores color cáncer. En ese caso no hay violencia, sólo hay patriotismo. Por el contrario, en las historias de Beigbeder aparecen grupos de agentes publicitarios escabechándose a una anciana jubilada de Miami, y en las historias de Ellis aparece un joven abogado, de probado éxito, adicto al capitalismo, que asesina sólo con sierras eléctricas Black \& Decker. Las mentes estrechas recapacitan: aquí hay algo raro. ¿Dónde están los extraterrestres y los comunistas que siempre atacan mientras que el resto del mundo sólo se defiende? La violencia que cimbra la apatía es perniciosa, concluyen. Influye en nuestros hijos de forma nociva. Entonces, en un mundo de conceptos tan determinantes y simplistas, es necesario trastocar un poco los conceptos de violencia buena y mala. Que la confusión ayude a aclarar el asunto.

La brutalidad aceptada es clara: hay deplorables enemigos y musculosos héroes.

La rudeza de los escritores, a primera vista, no tiene un motivo claro.

La brutalidad aceptada es un cigarro cuyo humo tonifica, un olor poderoso, catsup que desea ser sangre, una amante que no complica nada en la vida.

La rudeza de los escritores es el cigarro y el enfisema que va cortando la respiración en un lento y largo estrangulamiento. Es un fétido olor real. Es sangre que sale de una arteria cercenada y que impacta. Es la amante que quiere que te divorcies para que repitas el error con ella.

La brutalidad aceptada es el saldo de una ideología que miente para llegar a otros fines. 
La rudeza de los escritores recicla la imagen del artista incómodo, lleno de ángulos, que destroza el ordenado mundo ideológico y ancla sus raigones en una realidad poco utópica. Es más humana y por lo mismo contradictoria. Sin embargo su violencia también nos lleva a otros fines.

Los dos tipos de violencia sólo se parecen en que son ficticias. Pero ambas suelen tener consecuencias reales. La brutalidad ficticia aceptada puede provocar violencia real en los espectadores, en la medida que no tiene referentes críticos en su propuesta. Su oferta es estrecha y estrechas son las mentes influenciables: es posible sentirse aludido y condensar la rudeza observada en algo palpable. Sin embargo, eso depende más de la realidad inmediata que de la brutalidad a la que se está expuesto. La rudeza de los escritores difícilmente logrará el mismo efecto: dudo que las mismas mentes dediquen tiempo a leer y, si acaso lo hacen, que sean capaces de sentir el ímpetu trepidante que se puede lograr con cualquier programa de TV. El problema es que la crítica estrecha está convencida de que esto es posible. Se encuentran persuadidos de que los aliens con láser son inofensivos, mientras que la agresividad literaria es de lo menos saludable. Sin embargo, también

14 hay otra razón: la violencia literaria toca fibras más delicadas.

¿Es posible humanizar a partir de escenas violentas? Probablemente. Un asesino que apuñala sólo muestra parte de su universo en ese acto. El origen de la brutalidad difícilmente será sólo por la violencia misma. Hay actitudes psicóticas, paranoicas; ácidas interpretaciones de la vida. Las propuestas artísticas que usan la violencia lo saben. En el caso de la literatura, esa rudeza también está íntimamente relacionada con otros elementos.

El arte y la violencia siempre han florecido juntos, pero los nexos que los unen suelen variar. Pero antes de llegar al sitio donde se encuentran los escritores referidos, es necesario detenerse en un peldaño anterior: J.G. Ballard. 


\section{El fuego redentor}

En Noches de cocaina, Ballard expugna los complejos turísticos de las costas españolas, pobladas por ingleses, franceses y holandeses. Sitios en los que el tiempo está suspendido. Un mundo sin acontecimientos. Las cuadrillas de gente que ahí languidecen, engrosan el número de los jubilados modernos: no tienen más de 55 años y ya no tienen obligaciones por cumplir. Sin embargo, la deliciosa abulia pronto se convierte en angustiosa inercia. Es un atisbo del futuro de la humanidad: casas con terraza y albercas frente al mar. Pero los huéspedes han dejado de pisar la arena; jamás se zambullen en los 'espejos zen' en que se convirtieron las albercas. Tirados en camastros, gastan su tiempo consumiendo medicamentos para aniquilar la angustia provocada por la carencia de actividad. En medio de esas comunidades estáticas existe un complejo: Estrella del Mar, donde uno de los jóvenes directores se ha hartado de ese futuro instalado en el presente.

¿Cómo contrarrestar el efecto anestésico de la vida segura? Administrando dosis de violencia. Estrella del Mar pronto se vuelve afecta al juego. Sus habitantes comienzan a ser testigos de robos menores, luego aceptan con gusto el tráfico de drogas. El Xanax es sustituido por la cocaína, el Prozac por la heroína. El mismo directivo inconforme, Bobby Crawford, comienza a organizar persecuciones por la bahía que terminan en colisiones con fuego y disparos. Poco a poco, los jubilados reviven. Observan las canalladas con ojos expectantes. Desde las gradas del mundo ficticio, admiran el escenario de lo real. Luego vienen las violaciones. Espectáculos en amplios estacionamientos donde un hombre ataca a una mujer mientras los jubilados observan desde sus autos. Después Crawford incendia coches, lanchas y casas. El fuego se torna una cara atractiva de la violencia. El único fin es reactivar la ajada e inamovible vida de Estrella del Mar. Y el efecto es el deseado: se comienzan a inaugurar galerías de arte, los retirados toman cursos y se comienzan a ejercitar. Vuelven a estar vivos. La violencia de Crawford intenta cambiar el orden de las cosas: 
No...-Crawford se detuvo y me tomó de la mano.- Sí que importa. Charles, así va el mundo. Has visto el futuro y no funciona ni pasa nada. Los Costásoles de este planeta se están extendiendo. Los he recorrido en Florida y Nuevo México. Tendrías que visitar el complejo Fontainebleau Sud en las afueras de París... una réplica de estas residencias, pero diez veces más grande. Costasol no es obra de un promotor de pacotilla; fue planteada con cuidado para dar a la gente la oportunidad de una vida mejor. ¿Y qué han obtenido? Muerte cerebral...5

El fin último de Ballard, a diferencia de Ellis, Beigbeder o Palahniuk, es la violencia. La violencia que otorga dosis de vida en un mundo anquilosado. Una violencia de reacción. Noches de cocaína no es el único sitio en donde explota esta propuesta. En Crash se repite la consigna: personajes hastiados de la seguridad y la rutina, que anegan incluso su vida sexual, deciden enamorarse de cicatrices, deformidades y amputaciones provocadas por los voluntarios choques automovilísticos. Todo ello en una suerte de escape hacia el caos, consecuencia de un individualismo extremo que provoca seguridad excesiva. Un desprecio a ese estado en el que ya no sucede nada si no está planeado con varios días de antelación para garantizar nuestra integridad.

El individualismo que explota en un escape caótico es una efigie tan antigua como 1935. Ese fue el año de la publicación de Auto de Fe, la única novela de Elías Canetti, el gran lector del siglo XX. Obsesionado con las multitudes como desfogue caótico del individuo, esos sitios donde se pierde la unidad para fundirse con el entorno, Canetti recrea uno de sus personajes más contundentes: Kien. Un profesor que recolecta varias obsesiones y las agrupa bajo una más poderosa: el extremo individualismo. Kien no sale de casa. Se refugia en su segura biblioteca. No quiere saber del mundo y sólo tiene noticias de él mediante las páginas de sus libros. La desdicha quiere entonces que Kien se case con la más vulgar de las mujeres. Una fémina de características tan espantosas que obligan al profesor a huir de su casa. Kien no lo soporta y queda inmerso en un mundo que tiene una terrible desven-

${ }^{5}$ J. G. Ballard, Noches de cocaina, 1996, México, Grijalbo, p. 172. 
taja: es preciso convivir con los otros. Su extremo individualismo se ve afectado, así que hacia el final de la novela, en un franco repudio al rasgo más característico de su personalidad, Kien se prende fuego junto con su biblioteca en medio de una fantasía que anima y dota de personalidad a los objetos de su estudio. Los extremos se tocan. El individualismo y la violencia coinciden en un punto. Es necesario reventar de alguna manera o de otra forma nos convertimos en los artífices de nuestra propia apatía.

La propuesta de Ballard indica que, en un mundo repleto de Kiens apáticos, individualistas y sin una masa cercana a la cual unirse, la violencia adquiere tonalidades terapéuticas. Crawford desea con toda el alma que los Kiens de los complejos turísticos se inmolen en un buen fuego. La propuesta de Ballard es antigua, pero jamás había sonado tan actual.

Sin embargo, Ballard no es Ellis ni Beigbeder. Ballard es mayor que ellos. Ballard conoció la guerra. Su crítica se reparte entre la violencia y la ausencia de la misma. A ambas les otorga la misma tonalidad nociva como Canetti al individualismo y al desaforado escape caótico. Durante la Segunda Guerra Mundial, el Ballard niño estuvo preso en un campo de concentración japonés. La violencia ahí vivida la relata en El Imperio del Sol, novela que decepcionó a muchos de sus lectores porque otorgaba el andamiaje real que estructuraba sus infiernos ficticios. La Guerra mundial fue la experiencia que hizo germinar, tanto en Ballard como en Canetti, las teorías que combinan el individualismo, el escape caótico y el fuego. Una violencia que se transforma y busca nuevos fines en, por ejemplo, Patrick Bateman, el personaje principal de Psicópata americano. ${ }^{6}$

El presente es una época más anestesiada. Los jóvenes escritores no conocieron en carne propia ninguna guerra. A pesar de ese ridículo remedo llamado guerra antiterrorista, que sólo sirve para exportar la

${ }^{6}$ Como simple dato anecdótico, es curioso notar que el actor que da vida al niño del Imperio del sol y al asesino de Psicópata americano en sus versiones fílmicas son el mismo: Christian Bale. 
masacre a sitios lejanos, no han vivido jamás en una sociedad afectada por el hambre, por el caos. Lo que conocen bien es un mundo seguro, donde hay que crear espacios de escape, a falta de masa, a falta de guerra. A punto de terminar 13'99 euros, Frédéric Beigbeder contestó en entrevista:

-La fiesta, ¿es algo importante para usted?

-Absolutamente. Es durante una fiesta donde encontramos, la mayor parte de las veces, a la mujer de la vida. Donde sucede el primer achicharramiento de neuronas, la primera vez que probamos drogas. Varios de los episodios de la vida de un hombre, que yo considero como importantes, suceden durante las fiestas. Vivimos alegrías naturales o artificiales pero alegrías al fin y al cabo. No me da pena para nada este pasado. Contrariamente a mis padres o a mis abuelos yo no he vivido guerras o el mayo del 68. Mi generación es más bien consentida. La sola guerra que yo he librado es la de la cocaína. Como dijo el escritor Jay Mc Inerney: "We have been through the cocaine war".?

Las celebraciones son nuestros experimentales remedos de guerras. Y no es una apología de la guerra, es más bien melancolía por aquel escape caótico tan bien narrado en 1935. Por lo mismo, estos escritores buscan una mayor violencia en sus libros, para que actúen como brutales píldoras contra la parálisis. No se trata ya de centros para jubilados, estamos hablando de sociedades enteras sumidas en la aburrición, en la apatía, en la inercia, en la pose. El futuro temido por Ballard se convirtió en el presente de Ellis. No es gratuito que sus asesinos se encuentren deambulando por exclusivos restaurantes en Nueva York, o que Beigbeder desfogue sus instintos psicóticos en Miami, ecosistema del estancamiento vendido como ícono cool. Chuck Palahniuk utiliza la boca de una anciana para decirlo:

${ }^{7}$ Entrevista realizada por Sylvain Monier, marzo de 2000, en www.chez.com. 
La gente ha estado trabajando demasiados años para hacer del mundo un sitio seguro y organizado. Nadie se dio cuenta lo aburrido que esto podría llegar a ser. Con este mundo lleno de propiedades privadas y límites de velocidad y lleno de zonas e impuestos y regulaciones, con todo el mundo probado y registrado y ubicado y grabado. Nadie dejó mucho espacio para la aventura, excepto aquella que puedes comprar. En una montaña rusa. En una película. De cualquier forma, siempre es de ese tipo de falsa excitación. Sabes perfectamente que los dinosaurios no se comerán a los niños. El público encuestado incluso desaprueba cualquier posibilidad de un falso desastre mayor. Y, debido a que no existe la posibilidad de un desastre real, de un verdadero riesgo, nos quedamos sin oportunidad de una verdadera salvación. Excitación real. Diversión. Descubrimiento. Inventiva.

Las leyes que nos mantienen seguros, son las mismas que nos condenan al aburrimiento.

Sin un acceso al verdadero caos, jamás tendremos verdadera paz. ${ }^{8}$

De alguna manera la violencia de estos escritores cumple con la tarea que Crawford soñaba. Ya no es la historia de un personaje creando violencia, ahora son autores que elaboran una intimidación. Pero además, utilizan la violencia de otra forma. Le encuentran utilidades humanísticas.

\section{Sueños psicóticos}

Advertía Ellis al principio de Psicópata americano:

Ésta es una novela y por lo tanto todos los personajes, situaciones y diálogos que en ella aparecen -a excepción de algunas esporádicas referencias a personas, productos y lugares por todos conocidos- son imaginarios y no se refieren a nadie en particular ni pretenden dañar los intereses de ninguna entidad.

${ }^{8}$ En Choke, 2003, London, Vintage, p. 159. Traducción mía. 
La brutalidad es ficticia, pero la crítica es real. La sangre es simulada, pero el entorno se sugiere innegable. La violencia, en efecto, no daña 'los intereses de ninguna entidad'. Son 'las esporádicas referencias' reales quienes lo hacen, por eso son una excepción, por eso están entre dos largos guiones. Su poder destructivo se potencia cuando se encuentran inmersas en el mundo violento.

Un ente real cometiendo una acción ficticia: Beckham rasurándose con navajas Gillette mientras sonríe a la cámara con mirada de agradable sorpresa. Buena publicidad. Un ente real cometiendo una violenta acción ficticia: Beckham usando la misma navaja Gillette para cortar el cuello de Victoria-Posh-Spice-Girl, dejando salir borbotones de sangre, mientras se ríe y tiene una pequeña erección. Mala propaganda. Psicópata americano es sólo mala propaganda.

La novela de Ellis está plagada de marcas comerciales, de esas 'esporádicas referencias por todos conocidos'. En dos páginas se pueden leer hasta 33 marcas. ${ }^{9}$ Sin embargo, las baterías de la crítica rara vez se enfilan hacia una marca. Están asumidas, son parte de un mundo normal. Luego la normalidad del mundo se diluye. El personaje principal, Patrick Bateman, tiene 27 años. Viste "un traje de lana y seda con seis botones de Hermenegildo Zegna, una corbata de seda Ralph Lauren y zapatos de piel de Fratelli Rossetti”. Patrick reflexiona sobre lo que más le gusta: él mismo.

Soy joven, no tengo escrúpulos, estoy altamente motivado y soy muy ingenioso. En esencia lo que digo es que la sociedad no puede permitirse el lujo de prescindir de mí. Soy una buena inversión. ${ }^{10}$

Bateman es adicto a las marcas: de trajes, de coches, de bares, de restaurantes. Sus novias son adictas a la cara lencería, a largas sesiones de gimnasio, de estéticas, de SPA. Tanto las marcas, como Bateman, van delineando el mundo deseado por el norteamericano promedio,

${ }^{9}$ En las páginas 32 y 33 correspondientes a la edición, 1992, México, Diana.

${ }^{10}$ Idem, p. 13. 
aunque también por muchos de los habitantes de la Tierra. Después llega la redentora violencia. El pujante Patrick Bateman da muestras de actitudes oscuras. Una fascinación por las biografías de Ted Bundy, el asesino serial de los setentas norteamericanos. Antes, el epítome del sueño norteamericano revisa las páginas de un diario con acentuada carencia de humanismo:

Vamos a ver..., modelos estranguladas, bebés tirados desde el techo de los edificios, niños asesinados en el metro, $[\ldots]$-recorre las páginas con excitación-, jugadores de béisbol con sida, más porquería de la mafia, congestionamientos, vagabundos sin casa, diversos maniacos, enjambres de maricones llenando las calles, madres de alquiler, niños que consiguen entrar en un zoológico y torturan y queman vivos a varios animales, más nazis... y el chiste es, la gracia final es, que todo eso pasa en esta ciudad.... [...] espera un momento, más nazis, estorbos, estorbos, vendedores de bebés, mercado negro de bebés, bebés con sida, bebés drogos, un edificio que cae encima de un bebé, un bebé maniaco...

Ellis hace añicos el mundo soñado realizando una simple tarea: alumbrar las partes oscuras que el ideal no quiere ver. La falta de humanismo en Bateman es preocupación moral en Ellis. Las marcas comerciales y la deshumanización empatan alegremente. Se complementan. Los bebés sometidos a dosis de salvajismo recuerdan a las jóvenes generaciones expuestas a la inclemente dieta de violencia y falta de sorpresa. Una vez más los ancianos prematuros de Martin Amis, ahora crucificados por la violencia. Bateman descubre que los humanos también pueden ser objetos de cierta marca, caros o baratos. Un joven como él, con el físico afinado, con el dinero suficiente, se vuelve un artículo de lujo. Un empleado sin glamour, sin dinero, es desechable.

Primero asesina a un perro chai-pei (carísimo, al que hay que operar las bolsas que se forman bajo los ojos para evitar infecciones) y luego degüella a su dueño, un homosexual. En ese orden de importancia. Más tarde, es el turno de un pordiosero. Después llegan las prostitutas. Éstas no gozan de mayor prestigio que un juego de falsa bisutería: 
Encuentro una [prostituta] en la esquina de Washington con la Trece. Es rubia y delgada y joven, y lo más importante, es blanca, lo que es una rareza en zonas como ésta. Lleva unos shorts ajustados, una camiseta blanca y una chamarra de cuero barata, y si se exceptúa un moretón en su rodilla izquierda, tiene la piel pálida, incluida la de la cara. [...] Detrás de ella con unas letras rojas de metro y medio de alto que hay al lado de un almacén de ladrillo abandonado, está escrita la palabra 'CARNE'. ${ }^{11}$

El prestigio es el único axioma legítimo. Los humanos son objetos desechables. Las marcas tienen personalidad propia. Es posible ser violento con los primeros (los menos importantes) usando las segundas (lo más importante). Las personas sin prestigio adquieren importancia sólo cuando se revisten de marcas conocidas. Patrick Bateman con dos prostitutas:

Le pongo unas minúsculas pantaletas de encaje de Christian Dior y luego me quito toda la ropa -excepto unos tenis Nike- y Christie también se quita la bata Ralph Lauren y queda completamente desnuda si se exceptúa una mascada de seda y látex de Angela Cummings, que le ato cuidadosamente alrededor del cuello y unos guantes de gamuza de Gloria Jose para Bergdorf Goodman que compré en barata. ${ }^{12}$

Ese episodio termina con feroces golpes proporcionados por un gancho de ropa y quemaduras provocadas por unos cerillos del Gotham Bar \& Grill. Sin embargo, el verdadero reto ocurre cuando Patrick comienza a eliminar a sus propias amigas y a las novias de sus amigos. Quemar ropa interior de almacén no provoca mucha emoción, pero inflamar un conjunto de Prada es una deliciosa locura que excita. Lo que hay dentro de los atuendos es dispensable. Entonces, junta a una puta de poca monta con una mujer adicta a la ropa interior Victoria's Secret. Ambas reciben el mismo trato. Lo único que tiene personalidad propia son las ropas que visten.

${ }^{11}$ Idem, p. 156.

${ }^{12}$ Idem, p. 160. 
A partir de ese momento, la mayor parte de los asesinatos narrados también son un bombardeo de marcas comerciales. Se mutila con un cuchillo italiano, se ponen periódicos del New York Times que impiden a la sangría manchar los sillones IKEA, los pañuelos de seda Cummings sirven para limpiar las vísceras sin marca. Una vez más la mala propaganda. Todo en los asesinatos es adquirible y desechable. La ausencia de humanismo es la verdadera cara de las marcas comerciales, del prestigio, del marketing. La supervivencia del Yo. El desprecio de la otredad. Comprar cierto auto o traje sirve para que los demás me vean. Yo soy lo importante, ellos deben limitarse a admirarme. El humanismo aburre, no hace comprar.

La violencia, ese referente continuo en las últimas generaciones, adquiere nueva tonalidad y muestra el lado fosco de algunos mitos modernos considerados benéficos. El prístino abogado luchando por la justicia y logrando el éxito se convierte en un agente de la trampa. Las marcas de prestigio, como sellos de alto estatus, deshumanizan. El éxito material como sinónimo de bondad forma parte de una confusión generalizada.

La violencia purifica, elimina los convenios sociales y se vuelve detestable para aquellos que necesitan de las breves hipocresías cotidianas para sentir que se avanza hacia buen fin. La inocencia ensamblada con el materialismo, otra herencia norteamericana. ¡Cómo va a ser tramposo ese abogado! ¡Es imposible que se aproveche de la necesidad de terceros! Ese médico, ¡cómo va ser poco respetable si maneja un Mercedes Benz! ¡Está en la labor por humanismo, no por negocio! ¡Cómo va estar frustrada esa mujer sólo porque compra compulsivamente!

Con sus contradicciones, Patrick Bateman nos muestra que el mundo ha cambiado. El auto ya no es el medio para llegar al trabajo. Ahora el trabajo es el medio para llegar al auto. La fama no es consecuencia de ciertos oficios. Ahora ciertos oficios se obtienen gracias a la fama. Así, los abogados no eligen la profesión para preservar la justicia: eligen un tipo de justicia para preservar su profesión. La proliferación de estudiantes médicos en las universidades no significa 
un sorpresivo brote de humanismo. Todo lo contrario. Los enfermos nunca desaparecerán. Siempre habrá moribundos, siempre habrá trabajo para conseguir esa casa, ese auto. Esos médicos y abogados no difieren mucho de Bateman. El fin ahora es el medio, y el medio se relega hasta el final.

Los productores de televisión lo saben. Las toneladas de programas que nos muestran cómo se hicieron ricos Britney Spears y Justin Timberlake, que nos dan una radiografía del éxito que gozan, siguen reduciendo los parámetros de superación en las mentes pusilánimes. Los patrocinadores saben que existen obsesivos de la limpieza, convencidos que el olor a limpia pisos es el natural, personas que utilizan más de 17 productos de higiene personal en el aseo diario. ${ }^{13}$ Saben que los jóvenes amantes de los bares con cadena, los aficionados a la exclusividad, los adictos a los salones VIP, siguen confundiendo poder adquisitivo con la idea de ser mejores personas. Pero esa mejoría sólo es la capacidad de ver a otros seres humanos bajo el cobijo de la ignorancia deshumanizadora. La humanidad de pronto es una ola de nuevos ricos que adquieren las marcas más caras pensando que eso forma parte del estatus. Ignoran el nexo que tienen con la deshumanización.

24 Luego se preguntan por qué el mundo está tan mal, de dónde viene tanta maldad. La ignorancia y el individualismo se asustan del libro escrito por Bret Easton Ellis. En su pueril razonamiento, tal vez crean que ahí está el origen de la violencia. Pero la imagen de Bateman los altera por su cercanía con una realidad que apoyan entusiastas.

La escapatoria elaborada por Ellis no es un activismo de izquierda. La lucha de clases no tiene nada que ver. Las fórmulas ideológicas no son parte de la solución, sino del problema. La misma quimera que hace pensar en un auto como un símbolo que convierte a su conductor en una persona prominente, en vez de ser simple corneta

${ }^{13}$ Bateman se levanta una mañana y usa los siguientes productos: Plax fórmula antiplaca, pasta de dientes Rembrandt, Listerine, un cepillo de dientes eléctrico Probright, un abrillantador Interplak, enjuague Cepacol, Shampoo Vidal Sasson y acondicionador Complex, en una obsesiva tarea que intenta reducir al protagonista en un autómata libre de cualquier esencia humana. 
del ego, se trasfiere a un militante convencido de que su ideología lo transforma en buena persona. No se da cuenta de que sólo se trata de un paliativo para su conciencia, que además le otorga un halo de unicidad. El humanismo no tiene nada que ver ni con las marcas, ni con la ideología de oropel. A últimas fechas, incluso es posible ver la combinación de ambas obcecaciones: Angelina Jolie adoptando niños del tercer mundo.

La violencia literaria se utiliza para evidenciar la otra violencia. La congénita, la escondida en estos lugares, en todas esas personas. ¿Sólo porque la sociedad no quiere ver la violencia del mundo ordenado estamos obligados a respetar su torcida congruencia? Ellis no lo hace. Regresa así el moralista detrás del cuchillo. El American Dream se vuelve el American Psycho.

Patrick Bateman es el espíritu norteamericano sin hipocresías. Hace todo lo que desearía hacer un hombre repleto de dinero, educado de esa forma. Es el individualismo que viola, mata y adquiere aparatos de lujo. Es la fama y el éxito sin límites, es todo lo que la publicidad hace creer que llegarás a ser. Es la ilusión de esa sociedad, es su héroe. Bateman realiza todo lo que aparece en Internet bajo los títulos Hardcore: BDSM, zoofilia, necrofilia, pedofilia, el sexo que cada vez tiene más adeptos. Bateman es el coche de tus sueños, la ropa de tus sueños, las escenas orgiásticas con las mujeres de tus sueños. Pero Bateman también es el vacío de las personas que sólo desean eso. Es el asesinato violento de tus sueños que elimina la vacuidad. El sitio donde todo es desechable y comprable. ${ }^{14}$ ¿Qué sucede cuando ya se tienen todos los coches, todas las mujeres, todo el sexo, toda la ropa, todo el vacío? Se agarra una clavadora, se elige a una buena amiga y se recrea el siguiente pasaje:

${ }^{14}$ El ideal social y la violencia en Bateman recuerdan lo que el Mariscal Francés Gilles de Rais dijo tras ser acusado de 34 asesinatos y 140 desapariciones (la mayoría de niños): "Yo hice lo que otros hombres sueñan. Yo soy vuestra pesadilla" (El País Semanal, n 1,539, 26 marzo 2006). Seis siglos después, el ficticio Bateman pone en tela de juicio el avance de la civilización. Él no es real, pero sus características lo son. Por lo mismo, no es coincidencia que otro joven escritor, J. K. Huysmans, haya utilizado a De Rais con el mismo propósito crítico cien años antes. 
Aunque el chardonnay le ha embotado los reflejos, el whisky escocés que tomé yo aguzó los míos. [...] La dejo inconsciente de cuatro golpes en la cabeza que le doy con la clavadora. [...] Entonces le estiro los brazos, colocándole las manos con las palmas hacia arriba en unas gruesas tablas de madera, y le clavo tres clavos en cada mano, esto hace que recupere la conciencia y se ponga a gritar. Después de rociarle los ojos, la boca, la nariz con un spray de autodefensa, le pongo un abrigo de pelo de camello de Ralph Lauren sobre la cabeza, lo que ahoga sus gritos, o lo que sean. [...] Bethany vuelve a perder el sentido y vomita. [...] Enciendo la Handycam Sony para poder grabar todo lo que sigue. [...] Me aprovecho de su estado de debilidad, me quito los guantes y, forzándola a abrir la boca, con las tijeras le corto la lengua. [...] Luego me la cojo por la boca, y después de eyacular y sacar la verga la rocío una vez más con el spray.

-Y otra cosa -grito, paseándome por el cuarto-. No es de Garrick Anderson. ¡El traje es de Armani! Giorgio Armani. ${ }^{15}$

La violencia de Ellis se torna real, en la medida que hace referencia a una sociedad pródiga en racistas, xenófobos, asesinos seriales, individualistas extremos, adictos al Xanax, obsesos del prestigio, de los coches, de las marcas. Perversiones que conviven alegremente bajo un barniz de tranquilidad políticamente correcto. Psicópata americano puntualiza en lo siguiente: hay demasiadas coincidencias entre un hombre con un Porsche, la ropa más cara, que asiste a una sala VIP, y un asesino serial. Sus motivos individualistas son los mismos. El resto del mundo es dispensable.

Entonces, la paradoja de las mentes estrechas y ordenadas aparece: asustados de un mundo violento, educan a sus hijos con los valores individualistas más estrictos, los que consideran más seguros. Serían felices si sus hijos tuvieran el poder y el éxito de Bateman. Pero el paquete viene completo. Ese poder, éxito y aspiraciones están basados en la misma deshumanización del asesino, de la violencia que tanto rehuyeron.

${ }^{15}$ En Psicópata americano, op. cit., p. 222-3. 
Con Bret Easton Ellis vemos el estrecho mundo real, diagramado con las pautas del ficticio universo de la violencia. Lo contrario no produce un efecto similar. Cuando la estrecha violencia real es la que afecta al matizado universo ficticio, sólo se producen malas obras artísticas, sólo hay esculturas de falsos niños ahorcados.

No es estrictamente necesario diseñar a un asesino para denotar violencia. Los primeros cinco libros del autor establecen situaciones y estados de ánimo de una violencia adquirida, congelada, imperturbable. Es la violencia más realista. Los yuppies son adictos a todas las drogas, pero el consumo carece de emoción. Las bellas mujeres sólo piensan en ropa, pero las compras han perdido su poder lenitivo. La frustración, entonces, es mitigada con cantidades industriales de Prozac. Las bondades apenas se sienten. Los desprecios, los maltratos y los ultrajes se hacen con el mismo tono usado para saludar. Incluso Patrick Bateman se torna un asesino serial sin mucha emoción. Más aún: la inflexión utilizada para narrar es impasible, como un zumbido constante pero sin variaciones. Forma parte de la crítica. La inercia de los personajes, narrada con indolencia, está presente en todas sus historias. La ficción vive sumida en el formaldehído de la apatía. La brutalidad de Ellis critica la desidia de una franja de jóvenes acostumbrados a todo y más. ${ }^{16}$

Utilizar la violencia como vehículo de la crítica no es tarea sencilla. Si alguien no lo cree, habrá que preguntarle al director cinematográfico Marek Kanievska y al guionista Harley Peyton. Ambos se dedicaron a lacerar con ardua meticulosidad la novela Menos que cero de Ellis en la pantalla grande. El filme se estrenó en 1987, sólo dos años después que la novela. En él, toda crítica se esfuma.

La novela describe, sin mayor acción, la vida de un grupo de jóvenes amigos. La temporada corresponde al verano. El ocio es parte

\footnotetext{
${ }^{16}$ Sobre narrar los excesos juveniles con pluma firme y helada, existe un antecedente que resulta sorpresivo por su precocidad: Azul casi transparente de Ryu Murakami. Una vorágine de heroína, pastillas, sexo y baja autoestima en un grupo de amigos que se acerca a la pesadilla casi generalizada, ocurrida cuando las ideologías terminaron por disolverse.
} 
fundamental de la historia. También lo son las drogas: cada personaje tiene a su dealer privado. Sin importar el día o la hora (despreciables parámetros de personas que trabajan), consumen todo tipo de estimulantes. ${ }^{17} \mathrm{Y}$ esto ocurre con la modulación del propio Ellis: sin que constituya un acontecimiento notable. De hecho nada es trascendental: los estéreos, los autos último modelo, las bacanales festivas, la entrada a los clubes nocturnos más exclusivos. Todo ello forma parte de lo natural. Sólo son elementos escenográficos para una vida rutinaria, henchida de aburrición.

Los personajes tratan de enamorarse pero nunca lo logran. Tampoco se preocupan mucho por ello. Son incapaces de terminar una frase. Los diálogos que aparecen en la novela siempre aparecen truncados. Una pregunta es respondida a medias, las personas se relacionan desde canales distintos. Cada quién desde su individualidad. No pueden recordar qué película vieron cinco minutos después de haber salido del cine. Son incapaces de discernir si el filme les gustó o no.

Nada, absolutamente nada en este mundo los hará reaccionar. Ni siquiera el cadáver de un pordiosero en un callejón. La muerte parece divertida, pero sólo unos minutos, después los amigos que descubrieron el cadáver, regresan a su vida privada de emoción, a su apatía natural. Ése es el énfasis de Bret Easton Ellis. Ése es el verdadero infierno.

Pues bien, la adaptación cinematográfica disuelve todo esto. Las horas que pasó Ellis tratando de retratar una generación congelada, en el filme termina siendo una historia con un mensaje claro: las drogas son malas. Los rasgos característicos de los personajes aparecen sólo a medias para dar prioridad a tres prototipos: una mujer enamorada, un hombre que decide seguir adelante con la vida y un drogadicto perdido. Esta historia, que tiene como hilo conductor un trío amoroso, podría pasar en los ochenta o en los setenta, en los veinte, en 1815. El sello generacional se pierde. Lo único que queda es una pésima lectura.

${ }^{17}$ El tiempo deja de ser axioma. El exceso determina. Al respecto obtengo un par de líneas de dos canciones. Morrisey recitaba con melancolía: "Everyday is like a Sunday". Beck aplicaba la ironía al emular a una mujer que decía: "Thursday night, I think i’m pregnant again." 
En ningún momento aparecen la apatía, el áspero nihilismo. En vez de esto, tenemos un dealer malo, un pobre drogadicto, una muchacha enamoradiza y un joven emprendedor. Los personajes de la novela no son ni malos, ni pobres, ni están enamorados, y mucho menos son emprendedores. ¡Ése es el problema! Están entumecidos en un abismo donde cualquier tipo de emoción o creencia se suspende.

Los creadores de la película jamás se atrevieron a usar la violencia como sí lo hizo Ellis. Sin la apatía que acepta la violencia, la historia es un melodrama aburridísimo que no dice nada nuevo. Convierte a los personajes en predecibles clichés. La película critica exactamente lo mismo que las mentes estrechas amonestan. Hay una feliz coincidencia. La novela, por el contrario, confronta a toda una generación. La pone delante de un sombrío espejo. Desnuda a una sociedad antes que darle coba. El efecto es igual al que produciría ver a un yuppie de los ochenta asustado porque alguien le informa que la iglesia es corrupta. Como si un joven de los noventa se pusiera a llorar porque le acaban de informar que la política se encuentra llena de trampas. Todo ello ya está arrogado. El denominador común es no creer en nada. Y esto también es noticia vieja. ¿No crees en nada? ¿Y qué tiene de nuevo eso?

\section{Los golpes de la crítica}

Una suerte distinta corrió la adaptación de la novela de Chuck Palahniuk, El club de la lucha. El motivo puede ser simple: su realizador es David Fincher, creador de videos musicales y anuncios televisivos. Franja en la que se pueden encontrar vanguardias artísticas que no tienen remordimientos morales. Pero también contribuye que la novela se editara por vez primera en 1996 y la película en 1999. Entre la película Menos que cero y ésta hay 12 años de separación. Suficientes y repletos de cambios, como para atreverse a utilizar la violencia como vehículo crítico, sin mayor reparo moral.

Sin embargo, las fechas de nacimiento de los realizadores también nos dicen algo. Los temas de ambos libros van dirigidos a una franja 
generacional específica. Si el lector alcanzó la madurez en los años sesenta, la identificación con la nostalgia por el amor, la inquietud por el exceso de información o el giro narrativo violento de estos autores puede ser descifrable pero tendrá poca relación con su realidad inmediata.

Así las cosas, el trío que logró el éxito fílmico El club de la pelea ostenta las siguientes fechas de nacimiento: el realizador, David Fincher, 1962; el guionista, Jim Uhls, 1961; y el escritor, Chuck Palahniuk, 1962. Ninguno de ellos pudo vivir con mente madura el mayo del 68. Son una generación post-ideológica. Forman parte de la Generación X, en la medida que Douglas Coupland nació en 1961.

El realizador que nos dio el bodrio fílmico Menos que cero, nació en 1952 y el escritor Bret Easton Ellis nació en 1964. Kanievska todavía conoció el final de la época ideológica, los ochenta llegaron en su década de treintañero. No lo imagino viendo MTV. Es diez años mayor que la Generación X, mientras que el autor de la novela es casi post Generación X. Del staff de ambas películas, el mayor es Kanievska y el menor es Ellis. Sin embargo, tal vez todo sea culpa de la precocidad de Bret Easton Ellis, cuyo Menos que cero fue un éxito a sus 21 años.

Vayamos entonces con El club de la lucha. La historia traza a tres personajes: el narrador y personaje principal, ${ }^{18}$ Tyler Durden y Marla. Entre ellos existe un triángulo amoroso, aunque el delta no lo sea tanto, porque el narrador y Durden son la misma persona. El primero es un hombre ordenado que no cesa de recordar la 'buena persona' que era. El segundo está harto de tanto orden. Repudia la nueva vida donde, en vez de ver revistas pornográficas, el pro hombre explora los catálogos de IKEA. Está harto del mundo donde los grupos de apoyo para cancerosos, tuberculosos, enfermos terminales, tienen la exclusividad del calor humano. El mundo donde nadie cumple sus sueños porque deciden sacrificarlos y ceñirse a la seguridad. El flamante sitio colmado de aburrición.

${ }^{18}$ Que en la novela carece de nombre propio, alentado la identificación. 
La consecuencia del hartazgo es la creación de clubes de pelea cuyo único propósito es confeccionar escapes caóticos esporádicos. Desfogar la frustración de la quimera moderna. Pero estos clubes pronto se vuelven un consorcio que también administra el caos en la ciudad. El proyecto Mayhem ${ }^{19}$ busca desquiciar a la ciudad. Contrarrestar el nocivo orden y la patológica seguridad.

A pesar del excelente bordado de Fincher, existen algunos huecos en el filme. En éste, el cerebro que imagina y organiza es Tyler Durden. En la novela todos contribuyen. Es Marla por ejemplo, quien descubre que la grasa humana es la mejor para elaborar jabones o crear inyecciones de colágeno para los labios. Palahniuk reparte la culpa entre todos sus personajes. Con ello, la historia final no es la de un hombre con personalidad múltiple, sino la de un mundo donde la violencia es una necesidad. Sin embargo, la escena del filme donde el narrador y Durden roban grasa humana de los desperdicios de un hospital resulta asaz representativa. La orden de Tyler es clara:

Nuestra meta son las grandes bolsas rojas de grasa de liposucción que llevaremos de regreso a la calle Papel y las mezclaremos con lejía y romero y se las venderemos de regreso a la misma gente que pagó por que se la sacaran. A veinte dólares la barra, ellos son los únicos tipos que pueden pagarlo. ${ }^{20}$

La efigie casi antropófaga del autor puede repugnar. Es parte de la maquinación. Pero no es el fin último. ¿Qué propósito se persigue con la imagen de señoras inyectándose grasa humana en sus labios?

${ }^{19}$ La palabra "Mayhem" se traduce como "mutilación criminal de una parte del cuerpo de otra persona", sin embargo, de forma coloquial es sinónimo de caos. "Something is in mayhem": algo es desastroso. Pero el nombre de ese proyecto sólo difiere en una letra del apellido del periodista británico Henry Mayhew (1812-1887), fundador de la revista Punch (Golpe), que también tiene una obra en cuatro volúmenes de nombre Labour and the London Poor (El trabajo y el Londres pobre), con claras tendencias anarquistas. Palahniuk declaró haber utilizado algunas travesuras de amigos suyos que eran meseros y anarquistas para darles un propósito más concreto en su historia.

${ }^{20}$ Chuck Palahniuk, The Fight Club, 2003, London, Vintage, p. 150. Traducción mía. 
¿Adónde se quiere llegar con el retrato de una mujer bañándose con su propia grasa? La violencia descrita no es patrimonio exclusivo de Palahniuk. En una realidad instaurada desde antes, resulta punto menos violento que las mencionadas señoras se inyecten grasa, se quiten grasa, se estiren la piel y se corten el sobrante. No es grasa humana con la que se hace el colágeno de las operaciones estéticas, en realidad es grasa de vaca. ¿Cuál es más violenta, la realidad, la ficción?

Y el mundo está lleno de estas apetitosas violencias encriptadas: modelos, actrices, Pamela Anderson. La violencia literaria de Palahniuk sólo dota de una dimensión más amplia la violencia real. Nos muestra el maderamen. Y de cualquier manera Tyler Durden no es la primera persona a la que se le ocurrió hacer jabón con restos humanos. ${ }^{21}$ Que nadie se alarme: en este caso es ficción. El mundo ya está repleto de indiscutible violencia que no nos cansamos de encubrir o poner de moda. ${ }^{22}$

Los discursos de Durden para justificar sus proyectos están henchidos de psicología. La angustia colectiva siempre está presente. Ese desasosiego que provoca la noción de la muerte, como el motor que impulsa a trascender. Volverse un superviviente, como dijo Elías

32 Canetti. Para el pensador vienés, aquel escape caótico que fundía al individuo con la masa era una reacción a la certeza de muerte. La cólera que provoca la muerte. Chuck Palahniuk extiende su enojo a una civilización pasiva, ignorante y reacia a creer que algún día morirá. La ficticia sensación de seguridad que provoca la abulia. La aniquilación

${ }^{21}$ Es curioso, una vez que terminé de escribir esta idea me di cuenta de que el sistema de autocorrección automática del programa Word en español, cambia sin consultar la palabra Tyler por la de Hitler.

${ }^{22}$ Como bono extra a la violencia del mundo, en una suerte de prolongación del arte 'provocativo', me topé en el diario Milenio (México, 27 de agosto de 2004) la crónica de una performance de una artista argentina de nombre Nicola Constantina. En su más reciente entrega, a la mujer se le ocurrió una idea genial: hacer jabones a partir de su propia grasa. Una vez más, la crítica dejó ver su casta artistique: la comparación que los aterraba era la de los judíos en los campos de concentración. Interesante: cuando tanto la novela como la película de Fight Club salieron, nadie mencionó nada al respecto. Basta cumplir la dupla: artistas de vanguardia-críticos de retaguardia para que el efecto Buena Conciencia se cumpla. 
de la necesidad por crear algo, por trascender. "Ésta es tu vida, y está terminando minuto a minuto", recuerda con tenacidad Durden. Por ello, los personajes son asiduos participantes de los grupos de apoyo de cáncer, tuberculosis, enfisema, sin que se encuentren enfermos: "los funerales no son nada comparados con esto, dice Marla. Los funerales son una abstracta ceremonia. Aquí sí obtienes la experiencia real de la muerte". Buscan con desesperación ese motor de vida, enfrentando cara a cara a la muerte, odiando la seguridad:

No me quiero morir sin algunas cicatrices. Ya no significa nada tener un cuerpo hermoso. Cuando veo esos coches completamente rojos, recién salidos de la exposición de un coleccionista de 1955, siempre pienso, qué desperdicio. ${ }^{23}$

Son personajes que se rebelan frente a una época en la que la expiración de las ideologías y la superabundancia de seguridad tienen anestesiados a los individuos. En la misma queja arremeten contra el ideal del joven confeccionado en décadas pasadas. Ni el pasado ideático ni el futuro utópico se permiten como refugio. "Demasiados jóvenes, no saben lo que quieren", dice un portero entrado en años al narrador. En los sesenta sí sabían qué querían: inmolarse por una ideología. "Demasiados jóvenes tratan de impresionar al mundo comprando demasiadas cosas", dice después el portero. De alguna forma tenían que mitigar la angustia colectiva los yuppies de los ochenta ya sin ideología. "Los jóvenes quieren el mundo entero", dice el mismo personaje. La realidad es que al grueso de los jóvenes de los noventas no les importa mucho el mundo.

Tyler tiene una respuesta dirigida a esas generaciones post-ideológicas, post-ambiciosas, enclavadas en el bienestar y la seguridad, que no orquestan su trascendencia a la muerte. Una respuesta que se convierte en una suerte de edicto contemporáneo. Como toda elegía moderna, viene acompañada de un machacante beat en una canción

${ }^{23}$ Idem, p. 48. 
cortesía de los Dust Brothers. Un sitio en el que confluyen cine, música y literatura para denunciar el hartazgo:

This is your life, good to the last drop. It doesn't get any better than this. This is your life and it's ending one minute at the time. Only after a disaster we can be resurrected. It's only after you've loosed everything that you're free to do anything. Nothing is static, everything is evolving, everything is falling apart. You're not your bank account. You're not the clothes you wear. You're not the contents of your wallets. You're not your bowel cancer. You're not your grande latte. You're not the car you drive. You're not your fucking Khaki's. You have to give up. You have to realize than someday you will die. Until you know that, you're useless. I say, let me never be complete. I say, may I never be content. I say, deliver me from Swedish furniture. I say, deliver me from clever art. I say, deliver me from clear skin and perfect teeth. You have to give up. You have to give up... Welcome to Fight club. If this is your first night, you have to fight.

Mientras Bret Easton Ellis busca el hartazgo del lector, Chuck Palahniuk implanta una reacción en sus personajes. Los dos usan la violencia como utensilio. Pero Tyler Durden no encarna una salida viable al hartazgo de nuestra época y Palahniuk lo sabe. No es la escapatoria final. Tyler se muestra cool todo el tiempo y, más que un personaje creativo, busca con obsesión la catástrofe. Por ello no es el personaje principal. Al final de la novela es eliminado. Tyler Durden es la antesala para reinventar el mundo de otra forma. Es el paso previo (con toda su violencia crítica) de algo más importante.

Poco a poco, el proyecto Mayhem termina siendo un refugio de militantes. No está bien visto emborracharse, cada miembro debe comprar un arma y llevar el dinero de su funeral en sus zapatos. Son activistas peculiares contra toda ideología, salvo aquella engendrada en la esquizofrénica cabeza de su líder. Se acercan a un terrorismo producido esencialmente por su honestidad:

Quería destrozar todo lo bello que jamás tendría. Quemar la selva del Amazonas. Lanzar clorofluocarbonos directo a la capa de ozono. Abrir 
las válvulas de desperdicios y destapar los depósitos de petróleo. Quería matar a todos los peces que no podría pagar para comer, y quemar las riveras francesas que nunca vería. ${ }^{24}$

Una subversión contra toda breve ideología incluyendo al progresismo ecologista que otorga medallas. Contra esos hilos conductores que ignoran procesos más complejos y desgarradores:

Durante cientos de años, los seres humanos han jodido y han tirado basura y se han cagado en este planeta, y ahora la historia espera que yo me ponga a limpiar después de que ya pasaron todos. ${ }^{25}$

Una mezcla de honesta frustración y redentora brutalidad que resulta más robusta a vivir soñando imágenes publicitarias, mientras limpiamos nuestra conciencia donando unas monedas a Greenpeace y separando la basura. No hay que malinterpretar: probablemente sea necesario salvar la tierra, pero hacer de ello el único hilo conductor, es excesivo. ¿Qué pasaría si el mundo estuviera menos poblado de personas correctas aunque irreflexivas, y más de personas irresponsables aunque reflexivas?

En un acto de irresponsable honestidad, Chuck Palahniuk niega los íconos y prototipos de su generación: la ecología, el progresismo, la seguridad. Los anestésicos que no permiten pensar con nitidez. Que sólo aquietan la conciencia. Ése es el verdadero fin de la violencia en El club de la lucha: destruir esos axiomas de civilización impuestos antes de comprender al ser humano. "Lo que tienes que entender es que tu padre es tu modelo de Dios." Sutiles honestidades que observan al ser humano sin hipócritas muletillas espirituales. "Y si nunca conociste a tu padre, si tu padre huyó o murió o nunca está en casa, ¿qué podemos creer de Dios?"26

\footnotetext{
${ }^{24}$ Idem, p. 123.

${ }^{25}$ Idem, p. 124.

${ }^{26}$ Idem, p. 140-1.
} 
La figura paterna en la familia Palahniuk no es precisamente consoladora. Su abuelo paterno mató a su esposa, luego intentó hacer lo mismo con su hijo quien, escondido bajo la cama, atestiguó el suicido final del padre. Años después, en 1999, como cumpliendo un destino trazado tiempo atrás, el padre de Chuck Palahniuk fue asesinado por el ex esposo de una amante en las afueras de Spokane, Washington. $\mathrm{Su}$ cuerpo fue calcinado. Sólo quedaron identificables los registros dentales. ${ }^{27}$ Está claro entonces, cuál es el modelo de Dios para este autor.

El arte y la violencia siempre van de la mano. Ambos encierran complejidades que obligan a pensar. No buscan nuestro reclutamiento a favor de alguna causa. ¿Cuántas imitaciones en la vida real existen del proyecto Mayhem? Ninguna. Ello, a pesar de que El club de la lucha es un recetario para lograr con éxito un desastre. ¿Cómo hacer NAPALM? Se mezclan por partes iguales jugo de naranja congelado y gasolina, o se revuelve arena para gatos y gasolina hasta que la mezcla resulte espesa. ¿Cómo crear un explosivo? Con "permanganato de potasio mezclado con azúcar en polvo. La idea es mezclar un ingrediente que se consumirá muy rápido con un segundo ingrediente que suplirá con el oxígeno suficiente para lograr que se queme. Esto se quema tan rápido que resulta en una explosión". ${ }^{28}$

Sin embargo, después de que la película saliera, el Departamento de Defensa de Estados Unidos enroló a David Fincher, entre otros directores de cine, para prever posibles ataques terroristas. No buscó al escritor de ideas raras, sino al realizador fílmico. ¿Quién resulta más inocente? ¿El gobierno o las mentes influenciables? Pero los proyectos de Tyler Durden tienen una diferencia diametral con cualquier secta: van contra de las ideas fanáticas, de cualquier ideología. Todo es parábola. Una ficción violenta que nos permite elucubrar el presente con vistas en su pasado:

\footnotetext{
${ }^{27}$ Chuck Palahniuk, Error humano, 2005, Barcelona, Mondadori, p. 132-3.

${ }^{28}$ The Fight Club, op. cit, p. 186.
} 
No tenemos una gran guerra en nuestra generación, o una gran depresión, lo que sí tenemos, es una gran guerra del espíritu. Tenemos una gran revolución contra la cultura. La gran depresión de nuestras vidas. Tenemos una depresión espiritual. ${ }^{29}$

Palahniuk coincide con Beigbeder. Y los miembros del proyecto arremeten contra la depresión propagada. Durden pide que le entreguen 12 licencias de manejo correspondientes a 12 sacrificios humanos. Las inmolaciones son lo inverso. Consisten en la elección de un ciudadano que sea un irrebatible fracaso que haya renunciado a sus sueños. La poesía vendida. Hasta ahí, la tarea resulta muy poco ardua. Luego lo obligan a revertir su situación poniéndole una pistola en la nuca. El caso plasmado en el filme es el de un dependiente en una tienda abierta las 24 horas. Durden predica con el ejemplo. Llega al local, saca su arma y le pide la cartera con sus credenciales. Descubre que el dependiente dejó truncos sus estudios de veterinaria. Durden le advierte con el cañón en su boca. Si no regresa a clases, si no se gradúa como veterinario, regresará para matarlo. Durden inspeccionará su progreso al día siguiente, en un mes, en seis meses, en un año. Si no se convierte en veterinario, si no cumple su sueño, perderá la vida.

La consigna es clara. Nada de que no estudié porque un golpe de suerte me convertirá en un ser famoso. Aquí sólo hay realidad:

Somos los hijos en medio de la historia, educados por la televisión para creer que algún día seremos millonarios y estrellas de cine y estrellas de rock, pero jamás lo seremos. Y apenas estamos comprendiendo esta realidad, dice Tyler. Así que no nos jodan. ${ }^{30}$

La amenaza de muerte en los sacrificios humanos, la noción de que algún día desapareceremos, la violencia inyectada, todo el vehemente compendio es útil para levantarse y abandonar la eterna antesala de la

\footnotetext{
${ }^{29}$ Idem, p. 149.

${ }^{30}$ Idem, p. 166.
} 
fantasía. Para dejar de ver con ojos anhelantes esa puerta con el rótulo FAMA Y DINERO, por la que nunca nos harán pasar.

Una espera que produce traumas y desórdenes mentales. "Tyler es una proyección. Es un desorden de personalidad disociada", dice el narrador, a lo que el desorden en cuestión contesta: "Tal vez eres tú $m i$ alucinación esquizofrénica." Cuando alguien crea una personalidad múltiple, se acerca a la esquizofrenia (conjunción de los términos disociación e inteligencia). La personalidad múltiple nace de un trauma que reparte el peso doloroso en dos o más temperamentos. El trauma que crea a Tyler Durden es provocado por la misma antesala que produce anorexias, bulimias, depresiones, suicidios. Agradezcamos al exceso de seguridad. Demos las gracias al sueño de popularidad que jamás se cumplirá. A esa fantasía de certidumbre que sueña que los suicidas sólo pertenecen a una franja específica con una anomalía genética, que eso jamás nos pasará a nosotros. Ignoremos que la tasa de suicidios en las últimas generaciones aumenta a una velocidad vertiginosa. Ignoremos la verdadera violencia. ${ }^{31}$

La estampa final de El club de la lucha, como la de Windows on the World, es un edificio colapsándose. Pero este edificio es el resultado de un ultrasonido que nos permite ver lo que ocurre en el interior. Ahí están Tyler, el narrador, Marla y los miembros de Proyecto Mayhem. Vemos el interior los personajes. Todos juiciosos de su entorno, todos hastiados. Percibimos la violencia creada, como escape a un mundo

${ }^{31}$ La naturalidad con la que el mundo contemporáneo ve el suicidio, me llegó la semana del 11 al 17 de octubre de 2004 en forma de noticias. En Milenio, el día 12 advertí el titular: "Jóvenes japoneses pactan suicidio colectivo por Internet." Eran dos casos. El primero involucraba cuatro hombres y tres mujeres que rondaban los 20 años, el segundo a dos mujeres de esa misma edad. Ambos grupos habían organizado el suicido a través de chats, inhalaron monóxido de carbono de sus autos. El día 16, en el diario La Crónica de Hoy, se refería el suicidio de un niño de 12 años que había obtenido bajas calificaciones. El niño sufría de alcoholismo y resolvió colgarse de una cuerda en su propio cuarto. Esto en la ciudad de México. En el terreno de lo anecdótico, y como consecuencia de lo leído, recordé una discusión estadística que tuvimos mi madre y yo. Ella enumeró a amigos que se suicidaron y yo también. A pesar de la diferencia de edad (mi madre me tuvo a sus 28 años), el número de mis amigos suicidas casi doblaba el de mi madre. 
cada vez más parecido a un parque temático. En este sentido, el edificio Parker-Morris que se desploma al final de la novela, resulta mucho más significativo que el WTC. La ficción iluminando la realidad, no la realidad elaborando burda ficción. En uno de los dos casos, la historia sí ha sido expugnada y ha demostrado sus contradicciones.

Como están las cosas, es suficiente que Durden sea consciente de su entorno, aunque no constituya la solución. La violencia sigue manteniendo su espíritu crítico y no se evangeliza como salida práctica. Jamás llega a ser la meta.

Pero hay una coincidencia. Las motivaciones de Tyler Durden para formar un ejército, son las mismas de Chuck Palahniuk, Bret Easton Ellis, Irvine Welsh y Frédéric Beigbeder para escribir. Por eso Tyler desaparece al final de la historia. En el mundo de la ficción está la violencia. En el mundo real, la creatividad. Y probablemente sea ésa la verdadera propuesta factible contra el hartazgo.

La creatividad y la violencia sostienen un nexo en los escritores señalados. Desde dos terrenos distintos (realidad y ficción) se hartan de lo mismo. Lo que asusta a las buenas conciencias es la creatividad más que la violencia. La creatividad descoloca. Es una forma de violencia. La violencia ficticia, la que procede de una arranque de creatividad, se acerca a la única forma viable de un arte que detona estereotipos. La violencia es el único valor que no se puede revindicar, no se puede explotar. Nadie puede aceptarlo como la meta a la que se quiere llegar. La violencia es el único estadio honesto que nos queda. El resto ya lo utilizaron, lo han convertido en palabras huecas, lo han gastado. La violencia, en un mundo de términos relativos, es lo único que sigue manteniendo su fuerza concreta. Sigue siendo contundente. Pero todo ese poder sería imposible si no estuviera la creatividad detrás. Imaginemos entonces una escena imposible, pero que también es real:

Al restaurante Windows on the World entra un joven con un traje impecable y lentes oscuros que tapan su mirada de psicótico. Avisa al edecán que es Patrick Bateman y que tiene una reservación en la mesa con la mejor vista del sitio. Minutos después, por la misma puerta, con 
un ojo morado, tres puntos en la frente y una costilla rota, entra Tyler Durden. Ocupa la misma mesa de Bateman, se sienta frente a él.

-Te imaginaba más parecido a Brad Pitt.

-La imagen no es importante-, contesta con una sonrisa Durden.

Dos figuras más se acercan a la mesa: un joven con atuendo de tenista se presenta, es Bobby Crawford. Regentea un complejo turístico para ancianos de nombre Estrella del Mar. Tras él, apenas levantando la mirada, se encuentra el hombre de mayor edad de todos. Tiene dos libros bajo el brazo, un saco que le queda grande y responde al nombre de Kien.

Una vez sentados, ninguno de los cuatro puede estar quieto. Se analizan. No son familia, pero en la fisonomía del otro descubren algo propio. Patrick Bateman rompe el silencio, una vez más dirigiéndose a Durden:

-¿Por qué vistes de forma deplorable? ¿No sabes que un hombre es lo que viste?

-Nadie es la ropa que usa. Nadie es el contenido de su cartera.

-Si tuviera en mis manos una sierra...

- ¿Eres incapaz de explotar si no tienes un artefacto en tus manos?

-Para eso sólo hace falta fuego-, responde Crawford. A Kien le brillan los ojos y recuerda aquellas épocas en que con la masa era suficiente.

-Pero si creas violencia utilizando un artefacto de este mundo, también estás contradiciendo al mundo-, contesta Bateman.

-La contradicción más efectiva es la más sencilla-, regresa Durden.

-Me hablan de un futuro que yo ya temía-, dice Crawford.

-Pero, ¿de qué están hartos?-, pregunta una mesera con sonrisa idiota que lleva varios segundos parada al lado de ellos.

-De tu mundo seguro y aburrido.

-De tus pretensiones por mejorar que sólo prolongan una fantasía que te mantiene estática.

-De tu ignorancia y falta de creatividad. 
-De lo único que tienes genuino: tu abulia que sólo es interrumpida por autos veloces, salas VIP y sueños de bodas con médicos o abogados.

La mujer entiende a medias y se va. Ellos se quedan en silencio.

-Yo estoy harto de los setenta-, replica Crawford, después de pensar unos segundos.

-Yo de los ochenta-, regresa Bateman con la quijada apretada.

-Lo mismo pienso de los noventa-, dice Durden.

-Qué suerte tienen, -se atreve a decir Kien-, a mí lo que me ha hartado es todo el siglo XX. 
CITAM Derechos Reservados.

La reproducción total o parcial de este artículo se podrá hacer si el ITAM otorga la autorización previamente por escrito. 